\title{
LIMITES MUNICIPAIS: ASPECTOS DE INTERVENÇÃO ENTRE MUNICÍPIOS NAS OBRAS DE IMPACTO AMBIENTAL
}

\section{Ailor Carlos Brandelli ${ }^{1}$}

\section{INTRODUÇÃO}

Nesses tempos de busca de desenvolvimento, geração de empregos e arrecadação de tributos, o ente estatal, no estudo delimitado pela análise do município, denota a busca incansável de seus gestores em trazer para os perímetros municipais grandes empreendimentos, como usinas hidrelétricas, frigoríficos, abatedouros, produção de biodiesel ou ainda, explorarem vastas áreas com o plantio de monoculturas buscando suprimir determinada categoria industrial, cuja matéria-prima se torna mercadoria de grande valor em face da demanda do produto manufaturado.

Assim, os gestores municipais usam de todas as artimanhas para verem instalados em seus municípios determinadas empresas de grande porte, cuja marca será lembrada por muitos anos como se decorrente de determinada administração. Os mandatos eletivos de quatro anos são consideravelmente curtos se levada em consideração à continuidade das diretrizes predominantes dos municípios quando de sua criação, geralmente voltados aos propósitos de um crescimento sustentável.

A economia globalizada que se apresenta tem demonstrando que grandes empreendimentos podem sucumbir em meses no caso de um simples movimento das bolsas de valores mundiais. $\mathrm{O}$ que antes representava o progresso se torna uma estrutura pesada e que não consegue gerar os empregos e impostos prometidos. Resta ao ente público administrar legiões de desempregados e ver cair por terra um sonho de crescimento.

Nessa seara, os municípios vizinhos absorvem considerável parcela dos impactos gerados, decorrentes desses empreendimentos, sejam eles prósperos ou não. A fumaça gerada pela queima de resíduos ou mesmo a modificação das águas de um rio para

\footnotetext{
1 Mestrado em Direito pela Universidade de Caxias do Sul, Brasil(2011). Atua como Procurador de Município no RS e atualmente dedica-se à advocacia privada.
} 
construção de uma usina transcende os limites municipais, cujos alagamentos podem causar prejuízos imensuráveis, sem que o prejudicado tenha concedido qualquer outorga em favor daquele que teve instalado em sua sede determinado empreendimento.

Portanto, o que se busca debater é a possibilidade de o gestor público municipal atuar de forma integrada no licenciamento ambiental de uma obra de impacto a ser sediada no município vizinho, já que seus efeitos podem exceder os limites territoriais. Trata assim de atuar numa espécie de ingerência ambiental, opondo-se uma ação corretiva ou mesmo preventiva com o propósito de salvaguardar um ambiente útil a todas as espécies, verdadeiros patrimônios comuns não só dos munícipes, mas de toda a coletividade.

\section{O Licenciamento Ambiental. Os entes atuadores e os aspectos de concessão}

Para análise do licenciamento ambiental é de grande valia inserir no presente estudo as competências dos entes e suas prerrogativas para licenciamento de obras de impacto ambiental. A abordagem inicia pelo IBAMA - Instituto Brasileiro do Meio Ambiente e Recursos Renováveis, detentor de competência originária e supletiva e posteriormente dos órgãos estaduais, no caso em tela a FEPAM - Fundação Estadual de Proteção Ambiental, órgão esse atuante no Rio Grande do Sul.

Pela interpretação da legislação vigente, em especial o art. 225, § 4 da Constituição Federal; art. 8, I, art. 10 e art. $11, \S 1^{\circ}$, todos da Lei Federal n. $.^{\circ} 6.938 / 81$ e art. $4^{\circ}, \S 2^{\circ}$, da Resolução CONAMA n. ${ }^{\circ}$ 237/97, se depreende que o IBAMA detém duas ordens de atribuições para fins de licenciamento ambiental: a competência originária e a competência supletiva. A competência originária se dá nos casos previstos no art. 10 da Lei Federal n. ${ }^{\text {o }}$ 6.938/81 e, em especial, de seu $\S 4^{\circ}$ e no art. $4^{\circ}, \S 2^{\circ}$ da Resolução CONAMA 237/97. As demais situações seriam dos órgãos de proteção ambientais estaduais.

Já a competência supletiva se dá toda vez que o órgão ambiental estadual seja inepto ou mesmo se baseie em estudos incompletos. Nesse sentido, são expressos os textos dos arts. 10 e $11, \S 1^{\circ}$ da Lei Federal n. ${ }^{\circ}$ 6.938/81. A respeito da competência supletiva do IBAMA, também se encontra na Res. CONAMA n. ${ }^{\circ}$ 237/97, que dispõe sobre o licenciamento ambiental, regulamentando em seu parágrafo segundo do art. $4^{\circ}$ a competência supletiva do IBAMA.

Tal informação é de grande importância, uma vez que se o gestor público busca submeter à apreciação judicial determinado licenciamento, pode optar por incluir todos os 
órgãos de licenciamento no pólo passivo da demanda, ampliando assim a discussão na demanda a ser proposta e obtendo importantes informações técnicas que podem nortear a decisão a ser proferida.

Ademais, se os empreendimentos de impacto ambiental se localizarem em região de área de Mata Atlântica, o que abarca grande parte dos municípios gaúchos mais desenvolvidos, a competência do IBAMA resta confirmada em face da declaração, pela UNESCO, no ano de 1993, de se tratar de RESERVA DA BIOSFERA, o que a configura como patrimônio público de interesse nacional, a teor do art. 225 , parágrafo $4^{\circ}$ da $\mathrm{CF} / 88$.

Além dos órgãos de licenciamento ambiental e das empresas empreendedoras figurarem no pólo passivo de eventual demanda, deve-se verificar acerca do foro competente para o ajuizamento da demanda. Por se tratar o IBAMA de órgão federal, a apreciação da lide deve ser de competência da Justiça Federal, nos termos do art. 109, inciso I e parágrafo $2^{\circ}$, da $\mathrm{CF} / 88$. Deve-se sustentar ainda que por ser um empreendimento de grande impacto ambiental, na maioria dos casos a demanda buscará obstar possíveis danos ao meio ambiente e aos cidadãos nele inseridos, pelo que as subseções judiciárias federais se demonstram mais céleres e abrangentes.

Doutra banda, quanto às concessões propriamente ditas, cujos aspectos decorrem das licenças emitidas pelos órgãos licenciadores, divididas em Licença Prévia - LP, Licença de Instalação - LI e Licença de Operação - LO, as mesmas são precedidas de Estudo de Impacto Ambiental - EIA e seu respectivo relatório - RIMA. O EIA tem como escopo jurídico atestar a viabilidade do empreendimento e a forma de sua realização garantirá ou não, a confiabilidade de seu conteúdo, sendo essa uma condição indispensável ao estabelecimento de medidas de mitigação, reparação, compensação, controle e programas de monitoramento ambiental dos impactos gerados.

Havendo a menor suspeita de uma condução duvidosa nos trabalhos, deve o gestor municipal submetê-lo à apreciação judiciária, sob pena de que sejam os órgãos ambientais licenciadores induzidos ao erro ou mesmo coniventes com a instalação de determinado empreendimento. Deve-se sempre considerar que a economia tem ditado as regras de conservação do meio ambiente, e ao que tudo indica, o trata como uma das tantas variáveis do empreendimento, conforme ensina Michel Bachelet: "para a economia, a ecologia não passa de uma simples variável; os recursos naturais são outros tantos input integrados nos factores de produção”. (1995, p. 162.) . Para o ente estatal a definição parece se assemelhar em muito, conforme se destaca: 
A economia ambiental focaliza o papel da natureza como fornecedora de matéria-prima ou como receptora de materiais danosos. Dentro dessa redução, encontramos o sentido de meio ambiente. Assim, meio ambiente deixa-se conceituar como um espaço onde se encontram os recursos naturais, inclusive aqueles já reproduzidos (transformados) ou degenerados (poluídos), como no caso do meio ambiente urbano (DERANI, 2005. p. 51).

Para César Modena, “a economia global tem, com objetivo intrínseco, elevar ao máximo a riqueza e o poder de suas elites econômicas, ao passo que o objetivo da legislação constitucional ambiental é elevar ao máximo a sustentabilidade da vida”. (2008, p. 103). Parece assim, pela doutrina destacada, existir grande dificuldade em conciliar desenvolvimento e sustentabilidade, analisando-se sob o prisma da economia.

A efetividade na prestação jurisdicional, no tocante ao tempo de duração da demanda, é medida salutar na busca da preservação ambiental, já que aparentemente somente o Judiciário tem a capacidade de frear a incessante voracidade da economia e dos entes políticos. Numa visão da atividade jurisdicional, alia-se o tempo à justiça, essa última imediata em aplicar o direito e dele extrair o julgamento. Para Antoine Garapon:

A justiça é precisamente procurada como substituto da política porque ela não pode deixar de fazer o direito, de se expor às excomunhões da comunidade científica ou da opinião pública. Quando a comunidade científica se deve pronunciar acerca de uma questão, ela dá a si mesma o tempo necessário e, por vezes, conclui pela impossibilidade de se pronunciar. [...] a justiça deve julgar com as informações que dispõe. (1996, p.169)

Por serem finitos os recursos, sua falta a todos atinge e os efeitos podem ser nefastos. Falar em preservação de recursos é falar na manutenção e existência da espécie humana. Deve-se promover assim a aplicação do direito ambiental não somente com e pelas forças do Estado, aguardando a atuação constitucional do Ministério Público, por exemplo, mas sim, incluir e envolver as autoridades e comunidades locais, legitimadas por sua existência e costumes até então praticados e que devem sempre ser preservados, caminhando para, em conjunto, agir na preservação desse "bem maior". Nesse sentido, Sergio Matteini Chiari, discorrendo sobre a classificação jurídica do direito ambiental, anuncia que "a tutela do ambiente é instrumento da própria tutela do ser humano" (1990, p. 21).

Em que pese se buscar no Judiciário a devida medida coercitiva, preventiva ou reparatória aos prováveis danos ambientais de determinado empreendimento, não se pode sempre esperar dele a devida prestação. Nesse sentido, muito bem assevera François Ost:

Nesta óptica, os juristas, por exemplo, não estão muito inclinados a considerar que os danos causados à natureza não são irreversíveis, nem necessitam de qualquer intervenção urgente: não se diz que, passado algum tempo, a natureza retoma os seus direitos? Apercebemo-nos contudo, hoje, de quanto esta imagem é enganadora: as intervenções humanas, que são cada vez mais maciças e mais concentradas no tempo, interrompem os ciclos naturais e, pelos seus efeitos cumulativos, aproximam-nos dos limiares da irreversibilidade. (1995, p. 109) 
Ora, reconhecidamente o modelo de gestão até então empregado pelos entes públicos está distante do modelo esperado para um desenvolvimento sustentável. Sendo o meio ambiente e sua degradação uma variável que a economia pouco considera quando da análise de determinado projeto e tendo ainda um judiciário que pensa suas decisões, de cunho ambiental, como se reversíveis os danos experimentados, pouco se pode esperar quando se pensa o futuro da humanidade.

A experiência diária no acompanhamento da atuação dos gestores tem demonstrado que em nome do progresso e de uma maior arrecadação de tributos e geração de empregos, se tornam "cegos" em sua atuação e passam a considerar apenas o aspecto econômico do empreendimento a ser instalado.

Para Sparemberger e Martins,

É preciso repensar a atual estrutura da sociedade, com o intuito de consolidar uma cidadania participativa, em que a coletividade possa interferir de modo positivo no meio em que está inserida, o que possibilita, sem dúvida alguma, agir em prol do desenvolvimento sustentável e também da preservação do meio ambiente. (2008, p. 161).

Em que pese o cidadão ter a possibilidade de discutir elementos de preservação ambiental pela via da Ação Popular, ou mesmo provocar o Ministério Público, para que ajuíze uma Ação Civil Pública, tem o gestor público a responsabilidade de atuar em nome daqueles que o elegeram, de maneira a garantir a sustentabilidade de seu município ou mesmo, precaver eventual ocorrência cujos reflexos possam inviabilizar a sustentabilidade propalada. Para Bachelet, "o importante é chegar a uma gestão do planeta, que deixe de ser suicida, como a que hoje se observa”. (1995, p. 196).

Nesse sentido, Bolzan de Morais:

A Ação Popular é um instrumento jurídico colocado à disposição do cidadão, e só a ele, para coibir a prática de atos lesivos produzidos contra os bens especificados na norma constitucional. Tem ela conteúdo transindividual, embora a legitimação que atribua seja individual, uma vez que os benefícios produzidos e/ou prejuízos evitados não serão incorporados ao patrimônio do litigante com exclusividade, mas comporão como que um patrimônio comum solidariamente titularizado e usufruível pela sociedade como um todo distinto. (1996, p. 196).

Nessa mesma seara, Alexandre de Moraes afirma que "a finalidade da Ação Popular é a defesa de interesses difusos, reconhecendo-se aos cidadãos uti cives e não uti singuli, o direito de promover a defesa de tais interesses". (2004, p. 193).

A análise da Ação Popular como um dos modos de cidadania participativa, demonstra cabalmente ser uma ferramenta poderosa do cidadão comum para controle dos interesses difusos. Entretanto, sua prática não se dá com a freqüência desejada, não porque 
inexistem fatos que se enquadrariam em seu objeto, mas sim, pela necessidade de contratação de um advogado para ajuizá-la. Tanto é que milhares de Ações Civis Públicas tramitam pelo Poder Judiciário, uma vez que o cidadão prefere provocar o Ministério Público a contratar um profissional para ajuizar a ação da qual é titular por força de norma constitucional, igualando-se, na legitimidade, ao parquet na Ação Civil Pública.

\section{Ingerência ecológica: aspectos de afronta à soberania dos entes municipais em nome do meio ambiente}

A idéia de soberania soa, num primeiro momento, ao fato de transgressão das fronteiras de países, remetendo assim para o ramo do Direito Internacional. De pouca efetividade, já que carente de um tribunal com capacidade e legitimidade para imputar penalidade ao transgressor, se tem uma idéia utópica de prestação jurisdicional quando os entes tutelados são países.

Ao longo dos anos, testes nucleares, descargas de resíduos radioativos nos mares e abandono de sucatas tecnológicas no espaço causaram e tem causado consideráveis efeitos ao ambiente. Das lições aprendidas, várias foram as normatizações criadas ao longo dos anos, sem que os efeitos fossem realmente sentidos pelos povos. Ainda é possível verificar que grandes países se sobrepõem em suas atuações em detrimento dos mais fracos, sem que nada seja feito em relação a esses. A falta de coerção nas relações entre países torna sensível qualquer tentativa de limitar a atuação dos trangressores.

O mesmo não se poderia dizer dos municípios e dos estados-membros. O sistema federativo existente no Brasil permite certa autonomia dos entes públicos, todos subordinados ao modelo jurisdicional existente. E diga-se mais, ainda que pela histórica separação de poderes de Montesquieu, se tem verificado uma considerável força do Judiciário em relação aos demais, num fenômeno denominado "judicialização da política". O controle da constitucionalidade dos atos e leis modificou singelamente o entendimento da clássica visão da "Separação dos Poderes" de Montesquieu, antes mencionado. Para ele, os juízes são definidos como "[...] apenas a boca que pronuncia as palavras da lei, seres inanimados que não podem moderar sua força, nem seu rigor” (1996, p. 179).

Para Jeferson Marin, por analogia em relação a forma de atuação dos gestores municipais, considera-se que:

(...) o poder desmesurado de alguns Estados, frente aos demais, acaba por privilegiar, persuasiva ou truculentamente, os interesses de seus cidadãos; isso, de várias maneiras. Tal desequilíbrio acaba na desvalorização de normas tradicionalmente aceitas, e leva à erosão de 
estruturas que até então sempre tiveram sua presença garantida nas sociedades. (2005, p. 134)

Nesses tempos de judicialização da política, em que "os atos dos administradores cada vez mais são passíveis do crivo judicial" (LUNELLI, 2006, p. 26), a preocupação que se apresenta ao gestor público é de cumprir a lei e paralelamente acompanhar sua interpretação constitucional pelos Tribunais do país, uma vez que é certo que o judiciário não pode se sobrepor ao administrador público, dada sua ilegitimidade ante essa seara privativa que encerra cada Poder da República. Todavia, é seu dever coibir abusos cometidos sob a invocação da discricionariedade administrativa.

Da análise superficial produzida em relação à atuação do Poder Judiciário na avaliação das ações de gestão da coisa pública, é que se pode traçar um parâmetro para o propósito de se promover a ingerência ecológica, buscando a intervenção nos municípios vizinhos ou mesmo, ainda que não limítrofes, mas potencialmente prejudicados por eventuais danos ambientais de grandes empreendimentos.

Para tanto, em se tratando dos ventos dominantes na Europa, Bachelet exemplifica o seguinte caso, que em muito pode se aplicar aos casos de industrialização de grandes centros:

A Grã-Bretanha produz cerca de dois milhões de toneladas de dióxido de enxofre por ano (...). Mas a estreiteza do seu território, a proximidade do mar e dos ventos dominantes do oeste desembaraçam-na de dois terços dessa poluição e ela permanece uma região verdejante. Em compensação, a Escandinávia, que recebe devido aos ventos de oeste e do sul as nuvens ácidas inglesas, alemãs e polacas vê os seus lagos esterilizados e suas florestas definham. (1995, p. 211).

O mesmo se pode aplicar em relação aos rios cujo leito é recortado por usinas hidrelétricas (UHEs) ou mesmo as modernas Pequenas Centrais Hidroelétricas (PCHs). Os impactos ambientais, ainda que num primeiro momento monitorados e avaliados pelo EIA e RIMA, podem apresentar efeitos que transcendam os limites territoriais em que estão instaladas. Assim, tendo o EIA abrangido a área de sua instalação, não alcançou verificar possíveis enchentes decorrentes de abertura de comportas ou qualquer outro sinistro que possa ocorrer e atingir os municípios que se localizam abaixo dela e que cujo abastecimento se dá pelas águas do manancial.

Tem-se um paradoxo na utilização do recurso ambiental: grande parte da população é beneficiada pela energia elétrica gerada e a população da cidade onde se encontra sediada a usina recebe considerável retorno em royalty pela geração de energia. Doutra banda, vários 
municípios sofrem diversos impactos decorrentes da atividade de geração de energia e não são beneficiados por nenhuma ação mitigadora dos prejuízos experimentados.

Assim, tem a autoridade pública municipal a motivação necessária para colocar em xeque o funcionamento de determinado empreendimento, quer seja no uso dos recursos hídricos ou mesmo por absorver os resíduos que são carregados pelos ventos e que transcendem os limites territoriais dos municípios.

Tal preocupação inclusive foi tema de deliberação na III Conferência Nacional do Meio Ambiente sobre mudanças climáticas, realizada em Brasília (DF), no período de 07 a 11 de maio de 2008. Dentre as deliberações adotadas acerca dos recursos hídricos, tratou-se da seguinte forma os estudos de impacto ambiental:

52. Realizar estudos de impacto ambientais mais amplos, levando em consideração bacias e sub-bacias, e submetê-los à consulta ou audiência pública antes de liberar atividades com alto potencial poluidor, pelos órgãos públicos federais, estaduais e municipais em conjunto com os Comitês de Bacia.

Notadamente, ainda que tenham nomes que soam bem aos ouvidos como o de Pequenas Centrais Hidrelétricas, seus efeitos ao meio ambiente expressam-se em grande desproporção ao nome que carregam e por vezes, seus estudos estão voltados à facilitar a aprovação de seu projeto, deixando, em segundo plano os riscos que causam ao ambiente onde serão inseridas.

Exemplo de tais efeitos se colhe diretamente no Estado do Rio Grande do Sul, na bacia Taquari-Antas, que contempla o Rio das Antas, cujo nascedouro se dá nos Campos de Cima da Serra até suas águas desaguarem na Lagoa dos Patos e por fim, chegarem ao Oceano Atlântico, ao desaguar a Lagoa nos molhes de Rio Grande. Nessa extensão, o Rio das Antas passa a denominar-se Rio Taquari, quando recebe as águas do Rio Carreiro e por fim, vem a desaguar no Rio Jacuí, que por sua vez se comunica com o Rio Guaíba, antes de sua tortuosa trajetória até a final Lagoa dos Patos. Trata-se de um importante subsistema denominado Antas-Taquari-Jacuí.

Tamanha é a importância desse manancial, que a bacia do Rio Taquari foi objeto de deliberação na conferência anteriormente mencionada, assim descrita:

54. Promover a revitalização total da bacia do Rio Taquari (parte alta, média, baixa) e garantir efetiva transparência na aplicação dos recursos destinados à sua recuperação socioeconômica e ambiental, com anuência da população envolvida. 
Diversas são as Usinas Hidrelétricas instaladas em seu leito. Seus efeitos são sentidos no município onde estão sediadas e mesmo nos que estão localizados às margens dos mananciais envolvidos. Dos nocivos efeitos, os municípios localizados abaixo do reservatório da usina têm verificado considerável movimentação dos níveis de água nas margens do rio, evitando assim a formação de vegetação costeira, o que aumenta o assoreamento do rio e conseqüente diminuição de seu leito, quer seja na profundidade e mesmo na largura.

E mais, com a variação do volume da água se dá por conseqüência a alteração do que os biólogos denominam "vazão ecológica" ou ainda "caudal ecológico", que nada mais é do que a quantidade mínima de água necessária para garantir a sobrevivência e reprodução das espécies aquáticas e demais usos, como navegação, agrícola e afins. Assim, se o EIA não contemplar o estudo da referida variação ou o fizer de forma equivocada, os danos para o ambiente e populações ribeirinhas serão de grandes proporções e poderão ser sentidos cumulativamente ao longo dos anos. Uma represa altera significativamente não só o rio em que está construída, mas seus efeitos podem refletir diretamente em toda bacia hidrográfica.

O subsistema mencionado, com base no Diagnóstico Ambiental da BHTA - Bacia Hidrográfica Taquari-Antas, realizada pela FEPAM (2001, p. 125), demonstra que nessa área de bacia existem corredores migratórios para diversas espécies da flora e fauna silvestre, que são constituídos pelas zonas de contato da bacia Taquari-Antas com as bacias do Rio Uruguai e Litorânea. Assim, são listados três grandes corredores:

- Corredor formado pelos Rios Carreiro e Guaporé (Taquari-Antas) e Rio Ligeiro (Uruguai), interligando por cima dos divisores de água as duas bacias.

- Corredor do rio Tainhas que interliga o trecho superior da BHTA com os maciços florestais da encosta leste do Planalto, na região litorânea.

- Corredor formado pela zona de transição entre a Floresta Estacional e a Floresta Ombrófila

Mista, no curso do rio Taquari-Antas.

Por óbvio que o Diagnóstico Ambiental acima mencionado demonstra ser de vital importância para manutenção de todo ecossistema a preservação da Bacia Hidrográfica. $\mathrm{O}$ que se denota é que embora sejam diversos os estudos de impacto ambiental de determinado empreendimento, ainda que beneficie determinado município, pode ele trazer consideráveis prejuízos para toda coletividade. Daí porque legitimada está a autoridade pública municipal a ajuizar a demanda cabível com o propósito de prevenir ou de se precaver de possíveis danos ambientais.

O problema alcança não só rios que cortam municípios e Estados, mas também é sentido por grandes bacias hidrográficas que têm em sua composição territórios de diversos 
países. A discussão, em nível internacional, esbarra em tratados e protocolos. Todavia, em se tratando de municípios, a prestação jurisdicional, em tese, poderia gerir métodos de minimizar os efeitos no ambiente. Para Alejandro Iza, conferencista no $8^{\circ}$. Congresso Internacional de Direito Ambiental, realizado em São Paulo, no ano de 2004, o problema de ações ambientais, cujos efeitos são transfronteiriços, merecem soluções rápidas, como segue:

\begin{abstract}
Entendemos que uno de los escollos más importantes a nível internacional en el manejo de ecosistemas compartidos consiste en percibir las ventajasque reporta una acción concertada teniendo em cuenta el imperativo de encontrar soluciones rápidas en un contexto caracterizado por la escasez, el cambio climático y sus posibles consecuencias negativas mas allá de las fronteras de un país determinado. Pero por sobre todas las cosas, consideramos que una de las principales dificultades para normas em materia de flujos ambientales radica en otorgarle entidad jurídica y reconocimiento al meio ambiente, no solo como proveedor sino especialmente como usuario del recurso hídrico con todas las derivaciones que ello implica en cuanto al tema de su representación al momento de asignar el agua en un contexto de usos concurrentes. (2004, p. 31).
\end{abstract}

Não se pode ignorar assim, que os problemas decorrentes dos empreendimentos localizados em um município podem alcançar outros que não foram contemplados no EIA e mesmo não compartilham dos tributos arrecadados com a atividade licenciada. Todavia, carecem "de acesso à informação ambiental, ou seja, é preciso antes de tudo conhecer a realidade do meio ambiente e as leis que regulamentam o Direito Ambiental". (SPAREMBERGER e MARTINS, 2008, p. 161).

O Relatório Azul da Comissão de Cidadania e Direitos Humanos da Assembléia Legislativa do Rio Grande do Sul, edição de 2007, asseverou a tragédia do Rio dos Sinos ocorrida em 2006 e que alcançou proporções nacionais quanto a sua divulgação. No artigo assinado por Rualdo Menegat, Doutor em Ecologia, menciona que:

Exemplo disso é a tragédia ocorrida no rio dos Sinos em 2006. Além da mortandade de peixes, a água que abastece milhares de pessoas ficou seriamente contaminada, e os ecossistemas do entorno foram danificados. Como tal contaminação foi cometida por empresas inescrupulosas, é evidente que os produtos que produzem, e por decorrência, também aqueles do Rio Grande do Sul, passaram a carregar a imagem do desastre, portanto, seu valor no mercado despencaram. Afinal, quem quer comprar sapatos às expensas de cem toneladas de peixes mortos? Com isso, há deterioração simultânea da paisagem, dos ecossistemas e da economia, de sorte a causar depressão social e mal estar cultural. Ou seja, isso não é sustentável. (2007, p. 360).

O caso em tela demonstra outro grave problema, já que o Rio dos Sinos abastece diversos municípios da região metropolitana do Estado. Ora, as indústrias de calçados existentes geram tributos ao município em que estão instaladas e parte para o Estadomembro, de tal sorte que grande parte dos municípios atingidos pelo grande acidente ambiental não percebem nenhuma parcela de tributos que possa pormenorizar os prejuízos 
experimentados. Assim, está legitimado o gestor a interferir, sob o pretexto da ingerência ecológica, em atividades ou licenciamentos localizados fora do perímetro de seu município, já que pode ser diretamente afetado pela atuação de determinado empreendimento.

Portanto, submeter ao judiciário a análise dos atos de licenciamento e instalação de empreendimentos cuja atividade seja poluidora ou possa causar riscos é medida salutar para que sejam guarnecidos direitos daqueles que dependem dos recursos naturais para sua sobrevivência. Para tanto, assinala-se o ensinamento de Menegat acerca da sustentabilidade:

\begin{abstract}
A palavra 'sustentar' vem do latim sustento e significa 'suspender por cima, suportar por baixo, equilibrar, proteger, consolar o espírito, conservar, fazer frente a'. Para o pesquisador, Ignacy Sachs, da École des Hautes Études en Sciences Sociales, a sustentabilidade tem cinco dimensões: ambiental, social, econômica, política e cultural, como tentei ilustrar com o exemplo da mortandade do rio dos Sinos. Esse exemplo pode ser estendido, também, para outras escalas: dos ecossistemas, a local, com a contaminação dos recursos hídricos por resíduos perigosos, tóxicos, e, até a familiar e pessoal, na medida que tais contaminantes e o stress gerado por tudo isso afeta a saúde das pessoas. Acabamos nos hospitais e nos tribunais da Justiça. Assim, podemos acrescentar também mais uma dimensão, que é a civilizatória, posto que o aumento da desordem ambiental é acompanhada da desordem social e com a crise dos valores civilizatórios. (2007, p. 360).
\end{abstract}

No mesmo sentido afirmam Rocha e Simioni, mencionando que "um colapso ecológico é, também, um colapso comunicativo. E um colapso comunicativo é, ao mesmo tempo, um colapso da sociedade como um todo". (2008, p. 92).

Os fatos narrados são suficientes para demonstrar a possibilidade de intervenção de um município em outro, como uma espécie de ingerência ecológica, sob o aspecto da prevenção ou da precaução, conforme o caso ou ainda de acordo com o quanto do empreendimento já realizado. Para Viegas,

Relativamente à precaução, significa cautela antecipada. Se a prevenção visa a impedir a ocorrência de dano conhecido, a precaução avança no ambiente de preservação da natureza, permitindo a adoção de providências tendentes a evitar o dano mesmo quando este seja incerto. (2008, p. 136).

Para Rocha e Simioni, as decisões individuais podem causar efeitos de alcance difusos. Ensinam que:

No campo dos conflitos ecológicos, essa distinção entre risco e perigo se torna bastante útil. Ela permite observar que decisões ecologicamente arriscadas são, ao mesmo tempo, perigosas para todos os que podem ser afetados por elas. (2008, p. 83). [...] enquanto risco é algo que deve ser assumido para não se perderem oportunidades irreversíveis, o perigo é algo a que se está submetido e que, portanto, não apresenta nenhuma oportunidade capaz de justificar essa submissão. (Idem, p. 84). [...] Os decisores só enxergam os riscos e suas oportunidades, enquanto os afetados só enxergam os perigos das decisões. (Idem, p. 85). 
Assim, a abordagem trazida, cujos casuísticos foram conhecidos e de grande divulgação na mídia se parecem suficientes para demonstrar a possibilidade de ingerência ecológica no campo dos limites municipais, sustentando-se a tese de priorizar a preservação do meio ambiente como forma de frear a intervenção econômica e a voraz tendência de gestores na busca de investimentos em seus municípios.

\section{A (in)suficiente prestação jurisdicional ambiental}

Não bastasse o regramento existente, o Direito Ambiental agrega e compreende muito mais que leis. Implica em obter conceitos advindos de outras áreas de conhecimento, ciências como a geologia, engenharias, algumas áreas da saúde e afins, todas voltadas para o que talvez seja a maior preocupação da humanidade nessa pós-modernidade: a finitude dos recursos ambientais.

O desafio da proteção ambiental principia pela delimitação dos bens alcançados por essa proteção. A previsão jurídica tutela, em princípio, os bens individuais relacionados à ação dos indivíduos, o que se torna insuficiente para a temática existente. Daí decorre a seguinte afirmação:

Os direitos socioambientais são claramente permeados por conceitos desenvolvidos por outras áreas do conhecimento, e revelam evidente inter e transdisciplinaridade dessa nova área do direito, em que os conhecimentos produzidos pela dogmática jurídica são insuficientes para atender à necessidade de novos paradigmas na relação do homem com a natureza. (SANTILLI, 2005. p. 98).

Aqui, a proteção ambiental, embora garantida constitucionalmente, ainda ensaia os primeiros passos, especialmente em relação à tutela jurisdicional. Ainda que se afirme que "as normas ambientais têm eficácia imediata; independem, portanto, de lei infraconstitucional. Estão localizadas no rol dos direitos fundamentais de terceira geração, alicerçados nos princípios da solidariedade e da fraternidade" (MODENA, 2008, p. 113), não parece ser essa sua real aplicação quando se tem em mente a efetividade dos julgados. Também não se pode esquecer, entretanto, que o país convive com diversos outros problemas sociais, de extrema gravidade e difícil solução. A ausência de saneamento básico, por exemplo, faz vítimas fatais por doenças que há muito se acham resolvidas pela medicina.

A constitucionalização do direito ambiental demonstra a importância que o constituinte da época deu ao tema. Todavia, essa importância apenas ganha forma se efetivamente refletida na conduta social. À atividade jurisdicional do Estado impõe-se a 
sustentação desse direito fundamental. Quando o povo confia ao seu governo a criação das leis, nada mais faz do que estabelecer um elo de confiança mútua. Leonel ilustra que o constitucionalismo "é um conjunto de promessas, é a tentativa de construir uma nova sociedade no futuro". (2003, p. 312). François Ost menciona que:

\begin{abstract}
A figura moderna do Estado de Direito pressupõe, precisamente, o respeito dessa confiança mútua. Estas obrigações recíprocas (obediência à lei contra promessa de respeitar as condições da delegação do poder) assentam numa fé partilhada, uma confiança geradora de segurança durável no futuro. (1999, p.216)
\end{abstract}

Não bastassem tais problemas, novas teorias vão surgindo na medida em que as ciência exatas e sociais evoluem. De tais teorias decorrem liames que são postos à mesa do judiciário para definição de conceitos éticos e suas possíveis aplicabilidades. Causa estranheza já que se torna o Direito uma ciência consultiva, cabendo aos magistrados decidir temas que escapam à sua alçada, como por exemplo, bioética, transgenia e afins.

Portanto, a preocupação na garantia de direitos, não só ambientais e de cunho social, decorre do emaranhado de questões apresentadas, que vão desde os interesses escusos dos aplicadores até a ausência de normas para garantia da tutela dos direitos que se pretende proteger. Embora o direito a um meio ambiente ecologicamente equilibrado não se encontra disposto no artigo quinto da Constituição, sabe-se que o mesmo a ele pertence, já que a doutrina assim o reconhece.

O formalismo da dogmática jurídica existente não permite uma interação dinâmica e eficaz na manutenção e garantia dos direitos humanos fundamentais, demonstrando-se em certos casos, capaz de negar o acesso de seus jurisdicionados por questões de legitimidade e atuação processual.

Na Carta de São Paulo - 2003, durante o $7^{\circ}$ Congresso Internacional de Direito Ambiental, no que se refere ao papel do Judiciário e o Processo Civil Ambiental, a conclusão tomada é a de que "o processo judicial deve ser célere, eficiente, evitando-se o formalismo e acentuando-se o poder de decisão do juiz". Por isso é que se demonstra histórica a busca por um sistema processual efetivo, cuja aplicação esbarra em conceitos históricos e formalidades em sua maioria desnecessárias.

\title{
Montesquieu ensina que:
}

As formalidades da justiça são necessárias para a liberdade. Mas sua quantidade poderia ser tão grande que chegaria a contrariar o objetivo das próprias leis que a teriam estabelecido: as questões não teriam fim: a propriedade dos bens permaneceria incerta; dar-se-ia a uma das partes os bens da outra sem verificação ou se arruinariam ambas em razão de tantas 
verificações. Os cidadãos perderiam a liberdade e a segurança, os acusadores não conseguiriam mais convencer, nem os acusados conseguiriam justificar-se. (1996, p. 601).

Do excesso de formalidades decorre a ineficácia das normas vigentes em relação aos seus subordinados, conforme ensina Bobbio:

O problema de eficácia de uma norma é o problema de ser ou não ser seguida pelas pessoas a quem é dirigida (os chamados destinatários da norma jurídica) e, no caso de violação, ser imposta através de meios coercitivos pela autoridade que a evocou. Que uma norma exista como norma jurídica não implica que seja também constantemente seguida. (2003, p. 47).

Em verdade, toda a sociedade espera que o Direito resolva, por qualquer comando que seja, os problemas de natureza ambiental e social. A sociedade espera que uma lei contrabalance degradação e preservação em uma equação denominada sustentabilidade. Os mecanismos existentes sejam de natureza constitucional ou infraconstitucional, não têm se demonstrado hábeis para atender ao contraponto que se apresenta: conter a degradação sem prejudicar o desenvolvimento humano e social.

Isso sem mencionar a bioética. Se tutelar direitos ambientais, cujas árvores ou animais, hipoteticamente mencionando, não têm voz ativa na sociedade, tratar de direitos voltados à vida, com os atores disponibilizando seus propósitos nos meios de comunicação existentes, torna ainda mais penosa a vida do julgador, ou mesmo, em segundo momento, a do jurista.

Sensível à necessidade de preservação ambiental, o ordenamento pátrio registra expressiva legislação ambiental, dispondo e regulando em grande parte o trato dessa questão. No entanto, não raramente essa proteção ambiental encontra obstáculos para sua efetiva concretização. E tais obstáculos representam-se, também, pela falta de adequada tutela jurisdicional. O Direito "começa a ficar defasado em relação a uma série de questões importantes da sociedade, em relação a problemas políticos decisivos e, principalmente, defasado quanto àquilo que chamamos de novos Direitos”. (ROCHA, 2003. p. 15).

Essa tutela ambiental, realizada por meio de ações judiciais que seguem os princípios e procedimentos do processo civil, destinado primeiramente à solução de conflitos entre individuais, tem registrado escassa efetividade, uma vez que sobre tais incidem as influências de um processo fundado em princípios que se regem por ótica distinta. As discussões sobre matérias estritamente processuais - estritamente pertinentes à ciência processual - constituem-se em óbices à tutela ambiental. A fragilidade do bem ambiental e a finitude dos recursos naturais reclamam tutela rápida e precisa. Para Leonel Severo Rocha, "é preciso que se tenham mecanismos efetivos de tomada de decisões para se poder produzir futuro". (2003, p. 319). 
Para Lunelli e Marin, atos que envolvem a coletividade em conflitos de direito material não possuem o adequado processo. Mencionam que "via de regra, buscam-se soluções em áreas diversas, inclusive na esfera política”. (2008, p. 24). E asseveram:

\footnotetext{
Mas no caso das ações destinadas à proteção dos direitos consignados na Constituição, o Estado tem um interesse a mais, nem sempre presente nas ações do Processo Civil: é o interesse no bem jurídico tutelado que, pela sua natureza, escapa do interesse apenas do autor e réu.

É o caso, por exemplo, das ações destinadas à tutela dos direitos difusos, como a proteção ambiental, a proteção do consumidor e a proteção do patrimônio histórico". (2008, p. 26).
}

Todavia, além da necessidade de reformulação do processo ambiental e da leitura das normas vigentes com o propósito de se operar efetivamente nas ações de cunho ambiental, há de se promover um entrosamento da ciência jurídica com outras ciências existentes. Um julgador, um legislador ou mesmo um jurista precisam ouvir dos sociólogos, cientistas, médicos e outros representantes dos mais diversos meios científicos, pareceres e entendimentos acerca de determinados temas voltados ao meio ambiente. Faz-se assim, uma aparente "abertura" do Direito, seguindo o ensinamento de Kelsen de que se "o Direito é aplicado por um órgão jurídico, este necessita fixar o sentido das normas que vai aplicar, tem de interpretar essas normas". (1998, p. 387).

Esse é o prisma em que se visualiza um modelo efetivo de aplicação do Direito, especificamente no ramo ambiental: a necessidade de se interagir com outras ciências em busca de uma decisão mais acertada e que seus efeitos alcancem de forma benéfica um maior número de pessoas. Para Rocha e Simioni a idéia é transformar "o desconhecimento ecológico em comunicação da sabedoria de que se é ignorante nesse campo e assim, produzir advertências e exigir precauções" (2008, p. 69).

Longe de se discutir capacidade postulatória ou objeto de uma demanda, há de se verificar a imediata e mais coerente prestação jurisdicional, frente à finitude dos recursos existentes, sob pena de se segregar à morte milhares de seres existentes em face de um desequilíbrio causado pelo embate do homem frente à natureza.

Logo, independentemente de ser esse ou aquele prefeito; esse ou aquele cidadão, ou mesmo, saber qual o foro competente para a demanda judicial. O propósito é de se obter uma digna e célere prestação jurisdicional, que alcance de forma efetiva os anseios da sociedade, gerando mais do que empregos ou tributos quando da implantação de empreendimentos capazes de gerar impacto ambiental, e sim, criando formas sustentáveis de uso e preservação do meio ambiente como rumo norteador das ações municipais. 
Como ensinam Lunelli e Marin:

Não há, nas ações envolvendo os direitos afirmados constitucionalmente que têm natureza difusa, o risco de que o Processo dê a alguém o direito que é de outro: se difuso o interesse, não há um único titular certo e, por isso, justifica-se acolher a pretensão protetiva formulada em juízo, independentemente de quem esteja a provocar a prestação jurisdicional. (2008, p. 46).

Por fim, a sábia lição de Bachelet: “[...] aliás, o único titular de qualquer direito é indivíduo e a única soberania admissível no domínio do ambiente é a do próprio ambiente. O Estado não passa de um prestador de serviços, aí como em qualquer outro lugar”. (2005, p. 328).

\section{CONSIDERAÇÕES FINAIS}

A abordagem apresentada demonstra a existência de uma incessante busca do crescimento industrial pelos gestores públicos municipais, ansiosos pela geração de empregos e aumento na arrecadação tributária. Nesse norte, loteiam o perímetro dos municípios, transformando-os em parques industriais ou mesmo dando guarida a empreendimentos cujos efeitos no meio ambiente podem tomar proporções irreversíveis.

Doutra banda, municípios vizinhos não são diretamente beneficiados com o empreendimento, de modo que se tornam vulneráveis a todas as formas de impacto ambiental possível, sem receberem quaisquer medidas compensatórias ou mitigadoras dos efeitos nefastos. A degradação ambiental pode atingir diversas cidades, transportada pelas correntes de ventos ou mesmo pelo leito de um rio. Corredores ecológicos de grande importância para todo ecossistema podem ser diretamente prejudicados quanto a sua utilização, alterando significativamente o ambiente de determinada área.

Portanto, o que se demonstra é a possibilidade de uma ingerência ecológica daquele gestor que, ao conhecer determinado empreendimento, avança na autonomia administrativa do município vizinho e pelas vias judiciais, submete à apreciação do Estado os riscos que entende estar exposto, bem como toda a coletividade.

Ao mesmo tempo, ao recorrer ao judiciário, não encontra nele a guarida necessária, já que embora vasta a legislação ambiental existente, a efetividade do processo ainda é obstaculizada pelos princípios de processo civil voltados à resolução de conflitos entre particulares. Todavia, diferentemente das ações de ingerência entre países, apenas de natureza civil, as ações contra municípios permitem submeter a lide nos Tribunais de Justiça 
que possuem legitimidade e força coercitiva capaz de reverter determinada situação e até mesmo responsabilizar civil e criminalmente os agentes públicos ou políticos envolvidos.

Assim, os estudos de impacto ambiental devem abarcar não somente os municípios que serão a sede do empreendimento, mas sim, levando em consideração todo o ecossistema em que se encontra inserido, tratando a sustentabilidade de forma mais ampla, cujos efeitos podem reverter em benefícios para uma variada gama de cidadãos.

\section{REFERÊNCIAS BIBLIOGRÁFICAS}

BOBBIO, Norberto. Teoria da Norma Jurídica. Tradução de Fernando Pavan Baptista e Ariani Bueno Sudatti: São Paulo: Edipro, 2003.

BRASIL. Secretaria de Articulação Institucional e Cidadania Ambiental. III Conferência Nacional do Meio Ambiente: mudanças climáticas. Brasília (DF): CID Ambiental, 2008.

BOLZAN DE MORAIS, José Luis. Do direito social aos interesses transindividuais. O Estado e o Direito na ordem contemporânea. Porto Alegre: Livraria do Advogado, 1996.

GARAPON, Antoine. O guardador de promessas. Justiça e democracia. Tradução de Francisco Aragão. Lisboa: Arquimédia, 1996.

FEPAM. Diagnóstico Ambiental da Bacia do Taquari-Antas, RS: Diretrizes Regionais para o Licenciamento Ambiental das Hidrelétricas. FEPAM (RS), 2001.

IZA, Alejandro. Aguas, flujos ambientales y conservacion de la vida silvestre. In Fauna, Políticas Públicas e Instrumentos Legais. Antônio Herman Benjamin, organizador. São Paulo: Instituto O Direito por um Planeta Verde, 2004.

KELSEN, Hans. Teoria pura do direito. Trad. de João Baptista Machado. $6^{\text {a }}$. Edição. São Paulo: M. Fontes, 1998.

LUNELLI, Carlos Alberto e MARIN, Jeferson. A autonomia do processo constitucional e a legitimação para agir na tutela dos direitos coletivos: a dimensão publicista da jurisdição. In Jurisdição e Processo. Jeferson Marin, coordenador. Porto Alegre: Juruá Editora, 2008.

. Judicialização da Política, processo constitucional e legitimação para agir no controle abstrato de constitucionalidade. Revista da Faculdade de Direito/UCS. No. 15, Caxias do Sul : Educs. 2006. 
MARIN, Jeferson. A constituição desconstituída: antecedentes históricos e o retrato das crises do estado moderno. Revista Científica do Instituto de Pesquisa Cenecista. Bento Gonçalves : FACEBG. Ano 3, No. 3, Dez/2005.

MODENA, César Augusto. A Constitucionalização de Gaia. In Direito ambiental e biodireito: da modernidade à pós-modernidade. Org. Agostinho O. K. Pereira e Cleide Calgaro. Caxias do Sul, RS: Educs, 2008.

MONTESQUIEU. O Espírito das Leis. São Paulo: Martins Fontes, 1996.

MORAES, Alexandre de. Direito Constitucional. 15a . Ed.. São Paulo : Atlas, 2004.

OST, François. A natureza à margem da Lei - A ecologia a prova do Direito. Tradução de Joana Chaves. Lisboa: Instituto Piaget, 1995.

O tempo do direito. Tradução de Maria Fernanda Oliveira. Lisboa: Instituto Piaget, 1999.

RIO GRANDE DO SUL. Assembléia Legislativa. Comissão de Cidadania e Direitos Humanos. Relatório Azul 2007: garantias e violações dos direitos humanos. Porto Alegre (RS): Assembléia Legislativa, 2007.

ROCHA, Leonel Severo. A construção do tempo pelo direito. Anuário do Programa de Pós Graduaçao em Direito. São Leopoldo: UNISINOS, 2003.

SANTILLI, Juliana. Socioambientalismo e novos direitos. Proteção jurídica à diversidade biológica e cultural. São Paulo : Ed. Pierópolis, 2005.

SIMIONI, Rafael Lazzarotto e ROCHA, Leonel Severo. A forma dos conflitos ecológicos na perspectiva de Niklas Luhmann. In Direito ambiental e biodireito: da modernidade à pós-modernidade. Org. Agostinho O. K. Pereira e Cleide Calgaro. Caxias do Sul, RS: Educs, 2008.

SPAREMBERGER, Raquel Fabiana Lopes e MARTINS, Ezequiel. Desenvolvimento e Direito Ambiental: A gestão democrática das cidades para a sustentabilidade. In Direito ambiental e biodireito: da modernidade à pós-modernidade. Org. Agostinho O. K. Pereira e Cleide Calgaro. Caxias do Sul, RS: Educs, 2008.

VIEGAS, Eduardo Coral. Gestão da Água e Princípios Ambientais. Caxias do Sul : Educs, 2008. 